\title{
Update on the use of inhaled nitric oxide
}

\author{
ROBERT M KACMAREK PhD RRT \\ Department of Anesthesia, Harvard Medical School, and Massachusetts General Hospital, \\ Boston, Massachusetts, USA
}

RM KACMAREK. Update on the use of inhaled nitric oxide. Can Respir J 1996;3(6):373-376.

A literature review on nitric oxide would identify thousands of citations on the biological implications of this molecule. From the perspective of respiratory care, the effect inhaled nitric oxide has on pulmonary vasculature is the most intriguing. Over the past five years inhaled nitric oxide has been shown to be useful in the management of oxygenation during acute respiratory distress syndrome, alternation of pulmonary vascular tone in persistent pulmonary hypertension in the newborn, and in the management of chronic pulmonary hypertension in both heart and lung transplant candidates, as well as other potential clinical uses. The key physioligical response is vasodilation of pulmonary vessels in communication with well ventilated lung units and the absence of systemic vascular effects by rapid binding to hemoglobin. Nitric oxide therapy is considered experimental. A delivery system is not commercially available. This has resulted in the development of makeshift delivery systems, many of which may have the potential for adverse effects.

Key Words: Inhaled nitric oxide

\section{Mise à jour sur l'utilisation du protoxyde d'azote en inhalation}

RÉSUMÉ : Une revue de la littérature sur le protoxyde d'azote identifierait des milliers de citations sur les implications biologique de cette molécule. Dans le contexte des soins respiratoires, l'effet que le protoxyde d'azote a sur le système pulmonaire est des plus étonnants. Pendant les cinq dernières années, le protoxyde d'azote en inhalation s'est montré utile pour oxygéner les patients atteints du syndrome de détresse respiratoire aiguë, dans l'atteinte du tonus vasculaire pulmonaire dans l'hypertension pulmonaire persistante du nouveau-né, et pour la prise en charge de l'hypertension pulmonaire chronique chez les candidats à une greffe cardiaque ou à une greffe pulmonaire. De plus, le protoxyde d'azote peut avoir d'autres utilisations cliniques potentielles. La clé de la réponse physiologique se trouve dans la vasodilatation des vaisseaux pulmonaires en communication avec des unités pulmonaires bien ventilées et dans l'absence d'effets vasculaires systémiques grâce à une fixation rapide à l'hémoglobine. La thérapie au protoxyde d'azote est considérée comme étant expérimentale. Un système de délivrance de cet agent n'est pas disponible sur le marché. Ceci a entraîné la fabrication de systèmes de délivrance de fortune dont un nombre important peuvent provoquer des réactions indésirables.
S nce the first reported clinical use of nitric oxide in infants appeared in The Lancet in 1992 (1,2), hundreds of abstracts and full papers addressing actual and potential clinical uses of nitric oxide have been published. Although most findings must still be considered preliminary and final decisions on the clinical use of nitric oxide must await results of prospective randomized clinical trials, it is difficult to imag- ine that inhaled nitric oxide will not find a place in clinical medicine. In this update, the basic biology of nitric oxide is reviewed as well as the status of the use of nitric oxide in persistent pulmonary hypertension of the newborn (PPHN), adult respiratory distress syndrome (ARDS) and miscellaneous other clinical settings. In addition, technical issues associated with the administration of nitric oxide are addressed.

Correspondence: Dr Robert M Kacmarek, Respiratory Care Ellison 401, Massachusetts General Hospital, Boston, MA 01460, USA. Telephone 617-724-4480, fax 617-724-4495 


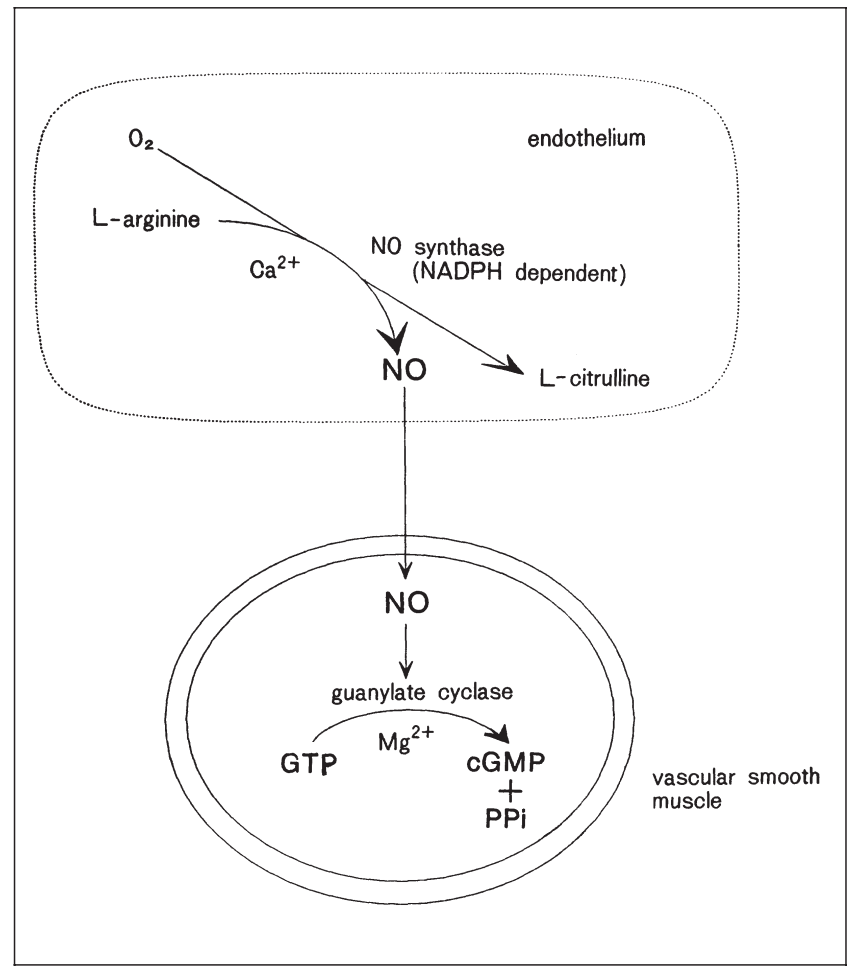

Figure 1) Biological pathway for the endogenous production of intracellular nitric oxide and the formation of cyclic guanosine 3',5'-monophosphate (cGMP)

\section{BIOLOGY OF NITRIC OXIDE}

Nitric oxide is endogenously produced by most cells in the body. It is involved with neurotransmission, bacteriostasis, tumour cell lysis, platelet inhibition, airway smooth muscle relaxation and vascular smooth muscle relaxation. Intracellularly, nitric oxide is formed from the amino acid L-arginine in the presence of calcium ion, oxygen and the enzyme nitric oxide synthase. Once formed, nitric oxide diffuses from the cell to receptor sites, where it binds with guanylate cyclase, causing the formation of cyclic guanosine $3^{\prime}, 5^{\prime}$-monophosphate (cGMP) from guanosine triphosphate (Figure 1). It is cGMP that produces smooth muscle relaxation. The in vivo half-life of nitric oxide is very short (about $5 \mathrm{~s}$ ), primarily as a result of the high reactivity of nitric oxide with hemoglobin, forming methemoglobin; nitric oxide has a greater affinity for hemoglobin than carbon monoxide.

The most interesting effect of nitric oxide during inhalation is regulation of vascular tone. Many systemically administered vasodilators (nitroprusside, nitroglycerin) release nitric oxide in the blood, resulting in generalized systemic and pulmonary vasodilation. However, inhaled nitric oxide only causes pulmonary vasodilation because of the speed with which nitric oxide reacts with hemoglobin. Essentially, free nitric oxide never leaves the pulmonary circulation. As a result, inhaled nitric oxide only dilates vascular beds that are ventilated, thus improving the matching of ventilation and perfusion. Contrary to systemically administered vasodilators, inhaled nitric oxide decreases intrapulmonary shunt fraction and increases $\mathrm{PaO}_{2}$.
TABLE 1

Actual and potential uses of inhaled nitric oxide

- Persistent pulmonary hypertension of the newborn

- Congenital cardiac anomalies

- Adult respiratory distress syndrome

- Chronic pulmonary hypertension

- Cardiac disease

- Pulmonary disease

- Asthma

- Cardiac surgery

- Lung transplantation

- Pulmonary embolism

- Acute myocardial infarction

\section{CLINICAL USES}

Over the past five to six years, nitric oxide has been used experimentally in numerous clinical settings (Table 1). A number of prospective clinical trials are ongoing to establish the effect of nitric oxide on patient outcome. To date, nitric oxide has been shown to affect physiological response in many settings.

Neonatal and pediatric: The two major conditions in which nitric oxide has demonstrated physiological response in neonatal or pediatric populations are in newborns presenting with PPHN $(1,2)$ and in infants with cardiac anomalies (3). In infants with PPHN, nitric oxide has been credited with some of the reduction in extracorporeal membrane oxygenation (ECMO) observed over the past few years (4). Inhaled nitric oxide in concentrations from 5 to $80 \mathrm{ppm}$ has resulted in marked improvement in arterial oxygen saturation by decreasing pulmonary vascular resistance, thus facilitating the transition from fetal to normal circulation. Several centres have reported infants who presented with ECMO indications having been successfully ventilated and extubated without ECMO (1-4).

Inhaled nitric oxide has been used both in the cardiac catheterization laboratory (3) and postoperatively in infants with cardiac anomalies (4). During catheterization, nitric oxide can safely establish the responsiveness of pulmonary vasculature and predict the effects of altered pulmonary bloodflow postoperatively. In the postoperative setting, inhaled nitric oxide reduces pulmonary artery pressure and improves oxygenation as the cardiovascular system acclimates to the redistribution of pulmonary bloodflow.

ARDS: The singular indication for nitric oxide that has received the most research attention to date is ARDS. Since Rossaint et al (5) first demonstrated that nitric oxide improves both pulmonary vascular resistance and oxygenation in ARDS, numerous articles (6-8) have been published regarding the clinical use of nitric oxide in this setting. Both our clinical results and those of Gerlach et al (7) indicate that the inhaled dose of nitric oxide that results in maximum improvement in $\mathrm{PO}_{2}$ is about 5 to $10 \mathrm{ppm}$, and that at doses higher than $20 \mathrm{ppm}, \mathrm{PaO}_{2}$ may decrease. This is in contrast to the dose of nitric oxide required to dilate the pulmonary vasculature maximally, which appears to be about $80 \mathrm{ppm}$. 
Nitric oxide has also been shown to reverse the increased pulmonary artery pressure and reduced oxygenation observed during permissive hypercapnia (8). In ARDS, the maximal dose of nitric oxide needed for oxygenation is 20 $\mathrm{ppm}$, but in many patients, doses in the range of $5 \mathrm{ppm}$ or less are maximally effective.

Asthma: Nitric oxide relaxes bronchial smooth muscle by affecting nonadrenergic-noncholinergic fibres, primarily in large airways, and has been shown to reduce bronchial tone in asthmatics at baseline (9) and following methacholine challenge (10). However, the magnitude of the response compared with standard sympathomimetics is limited. Thus, although inhaled nitric oxide is of academic interest in management of asthma, at this time it does not seem to be of use in the management of an acute asthmatic attack.

Chronic pulmonary hypertension: Inhaled nitric oxide reduces pulmonary vascular resistance in patients with chronic pulmonary hypertension as a result of both chronic pulmonary (11) and cardiac disease $(12,13)$. Preliminary data indicate that nitric oxide may be a useful tool to screen for responses to calcium channel blockers in patients with chronic pulmonary hypertension (14). Cockrill et al (14) have reported that patients who do not respond to inhaled nitric oxide do not respond to nifedipine, whereas about $50 \%$ of those responding to nitric oxide also respond to nifedipine. During pretransplant cardiac catheterization in cardiac transplant candidates, inhaled nitric oxide can safely determine whether the pulmonary vasculature is responsive (10). Semigran et al (12) also reported that inhaled nitric oxide can markedly elevate pulmonary capillary wedge pressure, potentially placing the patient with severe cardiac disease into left heart failure. In general, nitric oxide should be avoided in patients with poorly functioning left ventricles. In both of the above settings, 20 to $80 \mathrm{ppm}$ of inhaled nitric oxide is needed for maximal response.

Other potential clinical uses: Based on existing data, nitric oxide appears to have potential use intraoperatively during both lung and heart transplantation and during subsequent postoperative management. Because nitric oxide reduces platelet adhesion, aggregation and agglutination, and increases bleeding time (15), nitric oxide may be speculated to be useful in the management of pulmonary embolism and in the immediate period post myocardial infarction. In addition, it seems reasonable to predict that nitric oxide will be used chronically to manage patients with chronic pulmonary hypertension. However, simple administration technology for the spontaneously breathing patient must be developed.

\section{REBOUND}

Patients receiving continuous nitric oxide for longer than 4 to $8 \mathrm{~h}$ become dependent on the drug $(6,16)$. Why this is the case has yet to be defined. However, it appears that nitric oxide either decreases the endogenous production of nitric oxide or up-regulates the production of phosphodiesterase, the enzyme that metabolizes cGMP. Regardless of the mechanism, discontinuation of nitric oxide results in increased pulmonary vascular resistance and decreased oxy-

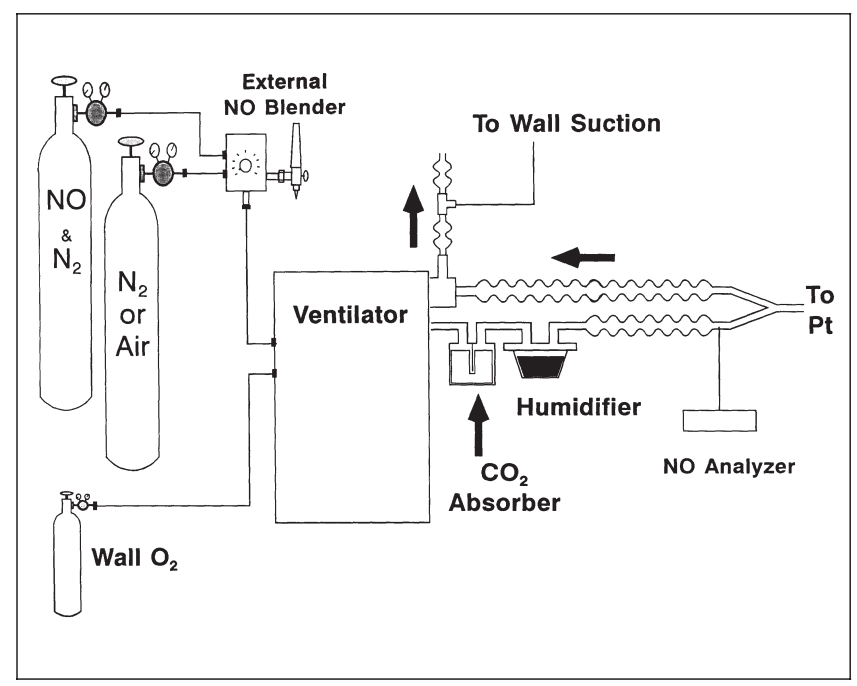

Figure 2) Dose response of inhaled nitric oxide for oxygenation and pulmonary artery pressure $(P A P)$. Values are means $\pm S D(n=12)$ expressed as a percentage (y-axis) compared with the initial value (0\% effect) and the highest alteration (100\% effect). Reproduced with permission from reference 7

genation. This may result in life-threatening arrhythmias, depending on the patient's cardiovascular status. To avoid the potentially deleterious effects of discontinuation of nitric oxide, it should be slowly weaned to less than $5 \mathrm{ppm}$ and the fraction of inspired oxygen $\left(\mathrm{FiO}_{2}\right)$ increased by $20 \%$ to $30 \%$ as nitric oxide is discontinued. Following discontinuation of nitric oxide, $\mathrm{FiO}_{2}$ can be slowly returned to the level before nitric oxide discontinuation over a 4 to $8 \mathrm{~h}$ period. In ARDS, the potentially detrimental effects of rebound can be minimized if nitric oxide is weaned only after $\mathrm{FiO}_{2}$ ( 0.40 or less) and positive end-expiratory pressure (less than $10 \mathrm{~cm} \mathrm{H}_{2} \mathrm{O}$ ) have been weaned and the patient's overall oxygenation status has improved.

\section{ADMINISTRATION ISSUES}

Administration of nitric oxide requires careful regulation of delivered concentration, the avoidance of nitrogen dioxide formation and the monitoring of methemoglobin production (17). Nitrogen dioxide production depends on nitric oxide concentration, $\mathrm{FiO}_{2}$ and time. The higher the nitric oxide concentration and $\mathrm{FiO}_{2}$ and the longer these gases are in contact, the greater the level of nitrogen dioxide formed. Ideally, nitrogen dioxide levels should be zero; practically, they should be kept below $2 \mathrm{ppm}$. Figure 2 illustrates a method of nitric oxide administration that allows precise control over nitric oxide and minimizes the production of nitrogen dioxide. As indicated in Figure 2, nitric oxide and nitrogen or air are preblended before entering the mechanical ventilator. With this setup, $\mathrm{FiO}_{2}$ and nitric oxide level are dependent on the setting of the blender and adjustment of the $\mathrm{FiO}_{2}$ control on the ventilator. Because gases other than oxygen and room air are entering the ventilator, the $\mathrm{FiO}_{2}$ control on the ventilator overestimates the actual $\mathrm{FiO}_{2}$ delivered. As a result, not only must nitric oxide and nitrogen dioxide be carefully monitored in the inspired gas, but $\mathrm{FiO}_{2}$ 
must also be monitored. Gas should always be monitored in the inspiratory limb of the circuit. Nitric oxide should be continuously monitored before the humidifier to prevent interference by water vapour and nitrogen dioxide should be periodically monitored at the airway opening. Ventilators used to administer nitric oxide should have a low internal volume to minimize the formation of nitrogen dioxide (17). A soda lime absorber may be placed at the inspiratory outlet of the ventilator to scrub nitrogen dioxide, but it also reduces nitric oxide levels, distorts inspiratory flow patterns and increases patient effort during triggering. Exhaled gas should be scavenged to avoid environmental build-up of nitric oxide and unnecessary exposure of health care workers to nitric oxide.

\section{REFERENCES}

1. Roberts JD, Polaner DM, Lang P, Zapol WM. Inhaled nitric oxide in persistent pulmonary hypertension of the newborn. Lancet 1992;340:818-9.

2. Kinsella JP, Neish SR, Shaffer E, Abram SH. Low-dose inhalational nitric oxide in persistent pulmonary hypertension of the newborn. Lancet 1992;340:819-20.

3. Roberts L, Lang P, Bigatello L, Vlahakes G, Zapol W. Inhaled nitric oxide in congenital heart disease. Circulation 1993;87:447-53.

4. Wessel DL, Adatia I, Thompson JE, Hickey PR. Delivery and monitoring of inhaled nitric oxide in patients with pulmonary hypertension. Crit Care Med 1994;22:930-8.

5. Rossaint R, Falke K, Lopey F, Slama K, Pison U, Zapol W. Inhaled nitric oxide for adult respiratory distress syndrome. N Engl J Med 1993;328:339-405.

6. Bigatello L, Hurford W, Kacmarek RM, Roberts JD, Zapol W. Prolonged inhalation of low concentrations of nitric oxide in patients with severe adult respiratory distress syndrome: effects on pulmonary hemodynamics and oxygenation. Anesthesiology 1994;80:761-70.

7. Gerlach J, Rossaint R, Pappert D, Falke KJ. Time-course and dose-response of nitric oxide inhalation for systemic oxygenation and pulmonary hypertension in patients with adult respiratory distress syndrome. Eur J Clin Invest 1993;23:499-502.

8. Young J, Brampton W, Knighton J, Finfer S. Inhaled nitric oxide in acute respiratory failure in adults. Br J Anaesth 1994;73:499-502.

9. Hogman M, Frostell C, Hedrenstierna G. Inhalation of nitric oxide
Two types of nitric oxide and nitrogen dioxide analyzers are available - chemiluminescent analyzers and electrochemical analyzers. Of the two, chemiluminescent analyzers are the most accurate but are much more expensive and difficult to use. For precision, chemiluminescent analyzers are required; however, for safety, electrochemical analyzers are adequate.

Because methemoglobin is formed whenever nitric oxide is inhaled, methemoglobin should be monitored before the initiation of nitric oxide, about $1 \mathrm{~h}$ after initiation and then at least daily. Although methemoglobin levels are not likely to be elevated if nitric oxide levels are low (20 ppm or less) (6), in the occasional patient methemoglobin is increased in spite of the level of nitric oxide administered (4).

modulates adult human bronchial tone. Am Rev Respir Dis 1993;148:1474-8.

10. Kacmarek RM, Ripple R, Cockrill BA, Block KJ, Zapol WM, Johnson DC. Inhaled nitric oxide: a bronchodilator in mild asthmatics with methacholine induced bronchospasm. Am J Respir Crit Care Med 1996;153:128-35.

11. Pepke-Zaba J, Higenbottam TW, Dinh-Xuan AT, Stone D, Wallwork J Inhaled nitric oxide as a course of selective pulmonary vasodilation in pulmonary hypertension. Lancet 1991;338:1173-4.

12. Semigran MJ, Cockrill BA, Kacmarek RM, et al. Hemodynamic effects of inhaled nitric oxide in heart failure. J Am Coll Cardiol 1994;24:982-8.

13. Loh E, Stamler JS, Hare JM, Loscalzo J, Colucci WS. Cardiovascular effects of inhaled nitric oxide in patients with left ventricular dysfunction. Circulation 1994;90:2780-5.

14. Cockrill BA, Kacmarek RM, Ginns LC, Thompson BT, Zapol NM, Semigran MJ. Inhaled nitric oxide is a selective pulmonary vasodilator without effects on anatomic shunt fraction in patients evaluated for lung transplantation. Am Rev Respir Dis 1994;149:A749.

15. Hogman M, Frostell C, Arnberg H, Hedenstierna G. Bleeding time prolongation and NO inhalation. Lancet 1993;341:1664-5.

16. Miller OI, Tang SF, Kiech A, Celemajer AS. Rebound pulmonary hypertension on withdrawal from inhaled nitric oxide. Lancet 1995;346:51-2.

17. Nishimura M, Hess D, Kacmarek RM, Ritz R, Hurford WE. Nitrogen dioxide production during mechanical ventilation with nitric oxide in adults: effects of ventilator internal volume, minute ventilation and inspired oxygen fraction. Anesthesiology 1995;82:1246-54. 


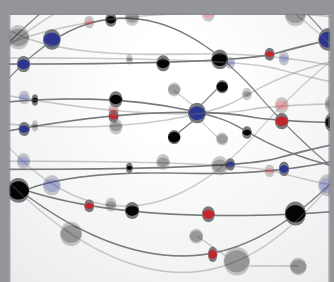

The Scientific World Journal
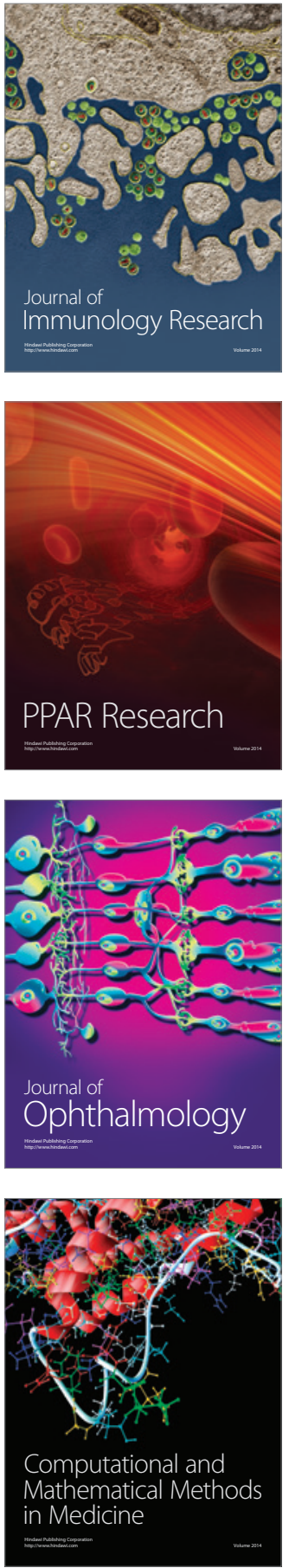

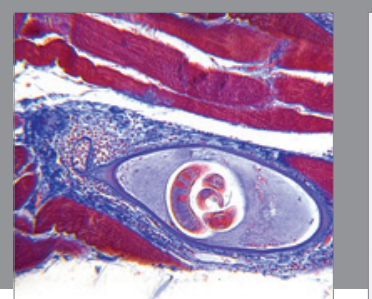

Gastroenterology Research and Practice

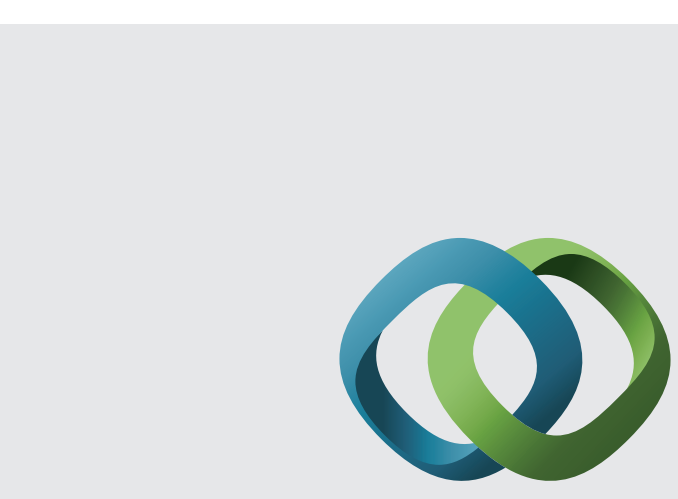

\section{Hindawi}

Submit your manuscripts at

http://www.hindawi.com
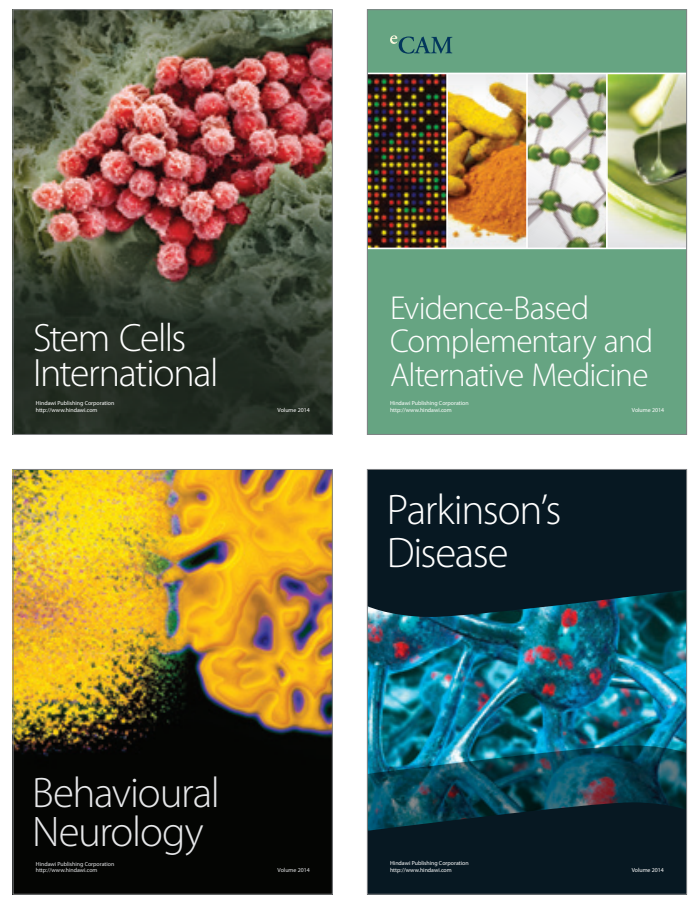
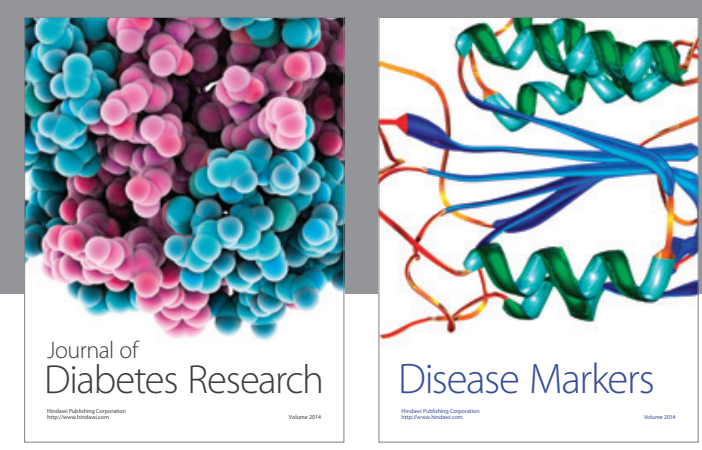

Disease Markers
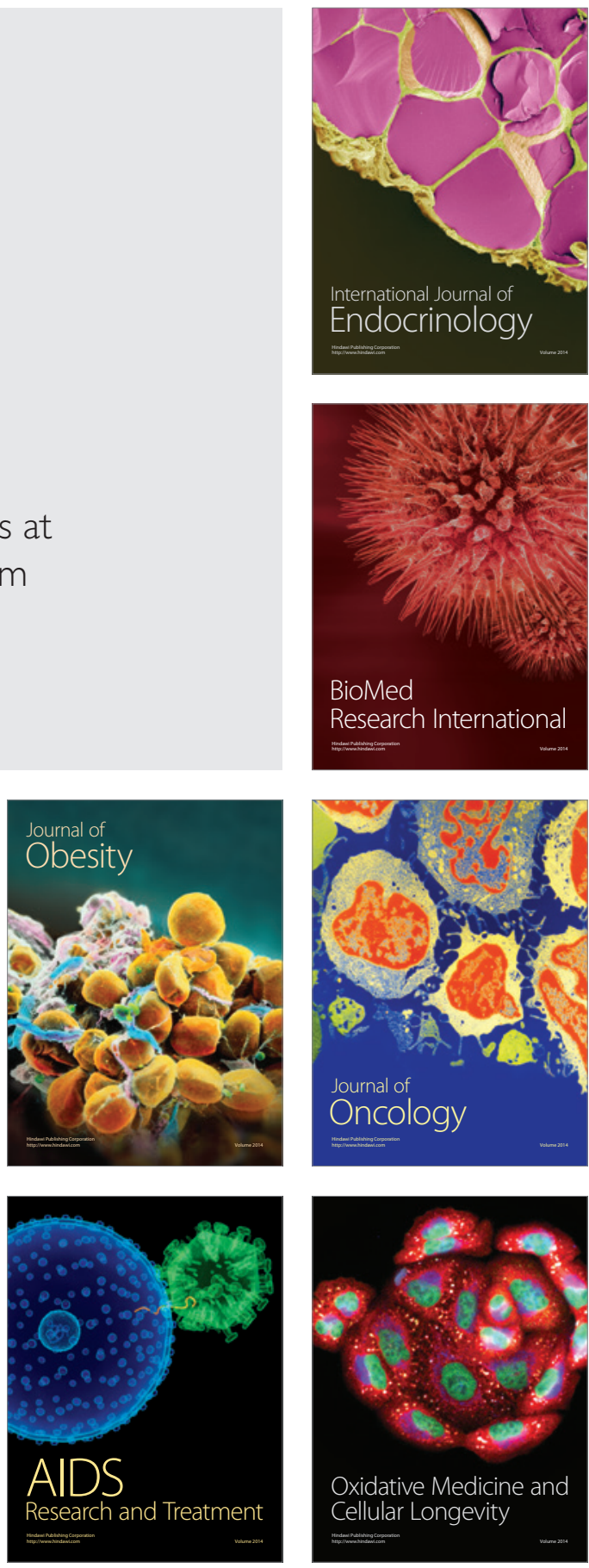